\title{
THE INTEGRATION OF INFORMATION AND INFORMATION TECHNOLOGY IN ACCOUNTING EDUCATION: EFFECTS ON STUDENT PERFORMANCE
}

\author{
Anne-Marie Eloff* \\ Stellenbosch University
}

Received: November 2015

Accepted: March 2016

\begin{abstract}
The role of chartered accountants in commerce has radically changed over the last decade. Regrettably, tertiary accounting education has not been able to keep up with these changes, resulting in a gap between the skills taught by universities and the skills required by commerce. To reduce this gap, SAICA issued the Competency Framework in 2010 which requires, in addition to the technical knowledge that chartered accountants are best known for, pervasive skills that all chartered accountants should possess upon entering the profession. However, the integration of these pervasive skills with the technical core subjects taught to accountancy students is limited. This article investigated whether one of the listed pervasive skills (namely competency in information and information technology) can successfully be integrated with a technical core subject (namely financial accounting) in such a way that the technical knowledge of the student is improved due to the integration. A Microsoft Excel consolidation model was created and presented to students to complete. Formal assessments and a questionnaire were used to determine whether the completion of the Microsoft Excel consolidation model, affected students' performance. The results showed that the completion of the consolidation model improved students' understanding of financial accounting.
\end{abstract}

Keywords

Accountancy, Pervasive skills, Information Technology, Higher education, Academic Performance

*Mrs A Eloff is a lecturer in the School of Accounting, Stellenbosch University, South Africa. [aeloff@sun.ac.za] 


\section{INTRODUCTION}

The role of chartered accountants (CAs) in commerce has changed dramatically over the last few years and long gone is the label that CAs are dull 'bean counters' or auditors. Instead, CAs have become renowned for leading top listed South African companies and for applying their skills and knowledge across all sectors as 'business consultants, tax advisers, entrepreneurs and financial managers' (Müller, 2011). The shift from CAs working primarily in a professional accounting practice to occupying various top positions across all business sectors, has resulted in a change in the skills that CAs require to be successful. Accounting education has however not changed accordingly and as a result has been criticised for providing graduates lacking the required skills (De Lange, Marx and Van der Watt, 2013:290).

Numerous studies have explored this gap that exists between accounting education and the expectation that the accounting profession in general and specifically employers have with regard to the knowledge and skills that CAs should possess upon entering the profession (De Lange et al., 2013; Hesketh, 2011; Bui \& Porter, 2010; De Villiers, 2010). To address this gap the South African Institute of Chartered Accountants (SAICA) developed the Competency Framework, in 2010. In addition to the technical knowledge that South African Chartered Accountants (CA(SA)s) are renowned for, the Competency Framework identifies other competencies, namely pervasive skills, which all CA(SA)s should demonstrate upon entering the profession. SAICA expects educators to offer a curriculum that integrates these pervasive skills competencies with the core subjects, without sacrificing technical excellence (SAICA, 2010: 6, 8, 16).

One of the competencies listed in the Competency Framework is proficiency in technology. Even though knowledge of information and information technology (here after referred to as IT skills) has formed part of SAICA's undergraduate programme for numerous years, the integration of IT skills with the professional subjects has become essential with the issuance of the Competency Framework. The use of IT skills, as part of almost every task performed by CA(SA)s, is emphasised and as a result IT skills should no longer be seen on its own, but as a vital part of all other competencies (including technical knowledge) identified in the Competency Framework (SAICA 2010:32).

At South African universities the integration of IT skills with core subjects is, however, limited (Barac \& Du Plessis, 2014). Barac and Du Plessis (2014) found that, except for auditing, IT skills were only integrated with the core accounting subjects to a limited extent. This could be attributed to the fact that (except for auditing) the other core subjects, such as financial accounting, are very technical. Educators therefore focus their teaching on ensuring that students' technical knowledge is of a high standard. SAICA however believes that if taught and assessed appropriately, the integration of pervasive skills with technical subjects will not sacrifice technical excellence, but rather substantially improve students' technical competencies (SAICA 2010:8). Evidence as to whether the integration of IT skills with a more technical subject, such as financial accounting, has an impact on students' performance (as expected by SAICA) is, however, limited (Boyce, 1999:200).

The objective of this study is to provide evidence as to whether pervasive skills can be successfully integrated with technical core subjects, in a manner that improves students' technical knowledge, as believed by SAICA. To achieve this objective the study reported in this article investigated whether the integration of IT skills with financial accounting has an effect on students' performance / technical competency. 
To answer the research question a Microsoft Excel spreadsheet assignment, which required students to simultaneously apply both IT skills and technical knowledge, was presented to students. At the university where this study was performed, it was noted that the financial accounting topic, group statements, is problematic for students at second year level. The reason for this problem is that students memorise the principles of the topic without understanding the practical application thereof. In practice, the application of group statement knowledge is computer-driven since most companies use either spreadsheet software or consolidation packages to prepare group financial statements. The Microsoft Excel spreadsheet assignment therefore focussed on group statements and was used to investigate whether the integration of IT skills with group statements, has an effect on students' comprehension of group statements.

The remainder of this article proceeds as follows: section 2 explains the research objective and section 3 presents a review of related literature. Section 4 explains the research design and method that was followed. The results of the study are presented in section 5 and concluding remarks are presented in section 6.

\section{RESEARCH OBJECTIVE AND CONTRIBUTION}

The objective of the study was to investigate whether the integration of the pervasive skill (IT skills) as per the Competency Framework, with financial accounting is beneficial to students' ability to master financial accounting. In order to achieve the mentioned objective the research set out to answer the following research questions:

- Does the integration of IT skills with financial accounting have an effect on students' performance?

- Does a more practical approach to a financial accounting topic have an effect on students' attitude towards the topic?

The study contributes by providing evidence as to whether SAICA's required integration of the pervasive skills with the core subjects results in an improved understanding of the technical competencies, as suggested in the Competency Framework. It further contributes to the discussion about the challenges currently faced in accounting education in South Africa, brought about by the changes required by SAICA and employers. It also explores whether and how the pervasive skill (IT skills), listed in the Conceptual Framework can effectively be incorporated into the financial accounting curriculum. The study is therefore of relevance to SAICA and accounting educators alike.

\section{LITERATURE REVIEW}

\subsection{The problematic nature of accounting education}

Due to the changing role of CAs in commerce and the resulting change in employers' expectations and requirements of CAs, the education of accounting students also needs to be adapted. Accounting education has been severely criticised over the last years, for teaching knowledge rather than skills (Barnett, 2009:439). Boyce, Williams, Kelly and Yee (2001) noted that due to the technical content of accounting, it is often lectured to students by using passive teaching techniques that focus on the transfer of knowledge. Siegel, Omer and Agrawal (1997:217) stated that the weakest aspect of using traditional teaching methods (which includes passive teaching 
techniques) is the absence of practical experience, which makes the learning of skills problematic. Gammie, Gammie and Cargill (2002:67) found that graduates believed that they had the technical knowledge required by the work environment, but that they did not feel equipped to transfer this knowledge into a practical work scenario.

With this in mind, SAICA developed the Competency Framework in 2010. The Competency Framework still requires that $\mathrm{CA}(\mathrm{SA}) \mathrm{s}$ have the exceptional technical knowledge for which they are renowned and it also identifies core professional qualities and skills, referred to as pervasive skills, that they should demonstrate upon entering the profession (thus after completing the required degree, traineeship and qualifying examinations) (De Lange et al., 2013:291).

Competencies included in the Competency Framework all support SAICA's vision for CA(SA)s, namely that ' $a C A(S A)$ is a leader with a very specific background in professional accountancy' (SAICA, 2010:4). From SAICA's vision it is thus clear that the pervasive skills identified in the Competency Framework are by no means a replacement of technical knowledge, but rather additional qualities that SAICA believes is essential, in developing CA(SA)s as leaders in the corporate world.

By moving away from a purely technical syllabus to a competency framework, SAICA has indicated that it requires a substantial change in focus in terms of the teaching and learning of accounting (Hesketh, 2011:4). Pervasive skills should be incorporated into all aspects of the syllabus and the integration of pervasive skills with core subjects is encouraged. It also calls for a move away from the traditional way of using written examinations to assess the technical competency of students, since such an approach causes the focus of accounting education to be the passing of examinations, which fosters a strong theoretical base, but not necessarily a good skills base (Botha, 2001:50). It is thus clear that the transfer and assessment of only technical knowledge is not sufficient any longer. Instead, graduates need to be equipped with the necessary skills to solve problems that they will be confronted with in practice (Springer \& Borthick, 2004:278). In the Conceptual Framework SAICA emphasises the use of practical experience as a means to integrate pervasive skills with technical competencies (SAICA, 2010: 8-9).

With the vast amount of technical knowledge that still needs to be mastered by accounting students, opportunity for practical application in an academic milieu is unfortunately limited (SAICA, 2010:11). There are, however, a number of pedagogies that can be implemented by educators to replicate practical application (SAICA, 2010:11). Examples of these pedagogies that will be suitable in an accounting environment include, case studies (Montaño, Cardoso \& Joyce, 2004; Boyce et al., 2001), business simulations (Fortin \& Legault, 2010:102; Gammie et al., 2002:73), project work and an assortment of other activities defined as experiential learning (Ballantine \& McCourt Larres, 2009:389-390). The use of real-life practical examples in accounting education creates an environment for sustainable learning (De Lange et al., 2013:286), since students are given the opportunity to solve problems by developing their own understanding of a situation and presenting acceptable solutions to the problem, instead of just memorising a solution given by someone else (Springer \& Borthick, 2004:278).

\subsection{Information and information technology as a pervasive skill}

Pervasive skills are categorised into three categories in the Competency Framework, namely ethics and professionalism, personal attributes, and professional skills. Listed under 'professional skills' is the requirement that CA(SA)s should be proficient in technology (SAICA, 2010:26). Among other, the use of computers to calculate information (for example by utilising spreadsheets) and to 
generate information, are listed as skills that a CA(SA) should possess (SAICA, 2010:30). IT skills are integrated into almost every task performed by a $C A(S A)$ in business and practice. It should therefore not be seen in isolation, but rather as a vital skill that forms part of all other competencies identified in the Competency Framework (SAICA, 2010:32). The appropriate knowledge of IT skills is therefore essential to the professional success of today's CA(SA) (SAICA, 2010:26).

The issuance of the Competency Framework brought a significant shift in focus as to how IT skills should be taught to students (Hesketh, 2011:4). The Competency Framework requires the integration of IT skills with accounting and external reporting and, among other skills, requires that CA(SA)'s should be able to use IT for financial reporting (SAICA, 2010: 32). Barac and Du Plessis (2014:64) found that the majority of South African universities offering SAICA accredited accounting programmes offer IT skills as a separate module or course and that the integration of IT skills into the core disciplines was, except for auditing, limited.

Recent studies found that employers expect CAs to possess certain IT skills, especially to be able to use spreadsheet software, and to be comfortable in applying these skills in their daily duties (Borthick \& Curtis, 2004:5; Barac, 2009). This need for graduates to be able to apply IT skills to their daily accounting duties and the requirement set by SAICA in the Competency Framework, makes it necessary for education to integrate computer skills with the professional subjects, which includes financial accounting (Wessels, 2005:90). This integration can also create the opportunity to use computer knowledge and skills as a means of learning (Boyce, 1999:193). Marriott (2004:59) suggests that incorporating computer technology in accounting education may assist in providing concrete practical experience to students, which should better equip them to apply technical knowledge. With the appropriate integration, computer-assisted learning has the potential to significantly increase educational outcomes (Boyce, 1999:192), which will lead to an improvement in accounting courses (Benke \& Hermanson, 1991).

\subsection{The integration of information and information technology in financial accounting education}

It is clear that the integration of IT skills with the professional subjects (which include financial accounting) is vital to ensure graduates meet the requirements of the business environment (Wessels, 2008). Yet worldwide, IT skills have not been sufficiently integrated with accounting programmes (Noor Azizi, 2009:74).

Studies relating to the integration of IT skills with accounting education are generally descriptive and focus on the suggested benefits or downsides of using computers in accounting education (Togo \& McNamee, 1995:2). It is strongly emphasised in the literature that the integration of computers into a course may not always contribute to the learning process and may in some instances even weaken the desired learning outcomes of the course (Boyce, 1999:195; Helmi, 1986). Izard and Reeve (1986) found that if the use of computers places too much pressure on students' already limited time, students cut back on repetitive problem solving that is of utmost importance to mastering financial accounting concepts. This results in students focussing on the completion of the computer project without understanding the underlying financial accounting principles. Computers should therefore only be used as a supplementary learning tool (Boyce, 1999:200).

Nevertheless, Boyce (1999) showed in his study (examining the 'role and impact of computer technologies in accounting education') that if applied appropriately the integration of IT skills 
can improve (financial) accounting education by simultaneously teaching students about (financial) accounting and assisting in the development of generic skills. One of the greatest benefits of integrating IT skills with financial accounting is the potential to address one of the major critiques against financial accounting education, namely the lack of practical experience (Siegel et al., 1997:217; Marriott, 2004).

As mentioned before, the use of case studies is one method to provide practical experience to students by using real-life scenarios that motivate students to develop a deeper understanding of the subject (Boyce et al., 2001:44, 46). Horsfield (1995:298) describes the purpose of case studies as a tool 'to apply theoretical knowledge to real-world scenarios'. By combining case studies with modelling software such as spreadsheet models, the learning experience is enhanced due to the emphasis on the interaction between financial accounting data, accounting processes and accounting information (Boyce, 1999:198). The purpose of modelling software is to assist students in thinking about a real-life solution to an accounting problem with which they will be faced in practice (Boyce, 1999:198).

The use of spreadsheet models assists financial accounting educators in overcoming some of the challenges (as mentioned in section 3 ) they encounter by enabling them to create challenging and engaging learning experiences that reduce surface learning (Marriott, 2004:56). According to Helmi (1986:106), one of the greatest advantages of the integration of spreadsheet models with (financial) accounting is that in order for students to build a spreadsheet model, they must first understand the existing relationships in a problem. This assists students in gaining a thorough understanding of the underlying financial accounting concepts and also enables them to apply this knowledge in practice.

In a study conducted by Marriott (2004), students were required to produce financial forecasts for a business plan by preparing a spreadsheet model. After completion of the case study, feedback was obtained from the participating students and it was found that they felt that the use of a spreadsheet model gave them the opportunity to put their financial accounting knowledge into practice, teaching them to do the actual financial projections and not just study the theory and calculations thereof.

Wu (1984) found that using a spreadsheet to prepare report formats (e.g. financial statements) forced students to understand the underlying logic of the report, as well as the data that is required to complete such a report. The use of spreadsheets thus resulted in an enhanced understanding of the required report. In a related study, Izard and Reeve (1986:163) also recognised that the construction of a spreadsheet template enables students to identify the critical inputs and thought process necessary to obtain a solution. This grants the students a comprehensive perspective on the problem, which results in a more meaningful learning experience.

Despite the potential advantages of modelling software (such as spreadsheet software) Boyce (1999:199) warns that modelling software may have a negative impact on student learning if the software is a source of frustration to students. When and where to use modelling software within the financial accounting curriculum is thus essential to ensure that students are not forced to 'explore' and 'discover' knowledge that would have been better taught or read about in a textbook (Leidner \& Jarvenpaa, 1995:283). Boyce (1999:195) contends that it is best to use computerbased accounting applications to assist in the learning of technical or applied content, since theoretical and conceptual material is probably best taught in other forms. In order to avoid potentially dysfunctional outcomes, the views of the above-mentioned authors need to be 
carefully considered before accounting educators decide where and whether computer-assisted learning should be introduced into the financial accounting curriculum.

It is clear from the aforementioned studies, that the integration of IT skills with financial accounting has the potential to improve students' performance if applied correctly and with due consideration of the learning outcomes (Boyce, 1999:204), but that if not applied correctly could also lead to a negative learning experience.

\section{RESEARCH DESIGN AND METHOD}

To answer the research questions a Microsoft Excel consolidation model (here after referred to as the consolidation model) was developed by the author and presented to students to complete. The consolidation model was developed in such a way, as to integrate IT skills with group statements, a topic of financial accounting. To ensure the validity and reliability of the consolidation model it was reviewed by two senior financial accounting lecturers. The study was pre-tested by a second year financial accounting lecturer before it was made available to the financial accounting students. Minor adjustments were made to incorporate their feedback and suggestions.

After the completion of the consolidation model, two approaches were used to investigate whether the integration of IT skills with financial accounting has an effect on the performance and attitude of students. First, written assessments were used to evaluate whether students' performance as assessed by using traditional assessment measures, showed an improvement after the completion of the consolidation model. Next, a questionnaire was developed to survey whether students felt that the completion of the consolidation model had improved their performance and attitude towards the subject. The results of both research tools were analysed to draw conclusions on the effect that the integration of IT skills with financial accounting has on students' performance and attitude towards the topic, and thus the subject.

\subsection{Background}

From experience gained through lecturing financial accounting as well as through one-on-one discussions with financial accounting students (herein after referred to as students), it was noted that one of the more challenging topics for students is group statements. Students struggle to grasp the practical application of group statements and often spend most of their time studying and memorising the consolidation journals, which includes intergroup transactions, and little time on understanding the core principles of preparing consolidated financial statements. At the university where this study was conducted, financial accounting students are introduced to group statements (more specifically to consolidations) in the first semester of their second year of studies. Students are taught basic consolidation procedures, which includes the consolidation of one parent company with one subsidiary and basic intergroup transactions that excludes the effect of deferred taxation. Lecturers primarily make use of traditional teaching methods, which includes examples being done in class. Students are also provided with ample questions that they can use to practise the underlying principles to ensure comprehension. At the end of the term the topic is assessed with a formal written test that makes up approximately $28 \%$ of their class mark.

After the formal assessment, students have a four to six week recess. Upon their return to class in the second semester, an unrelated topic is taught for two weeks, where after group statement 
classes resume, which now include the effect of deferred tax as well as more complicated intergroup transactions.

The teaching of group statements in the second semester builds on the knowledge gained in the first semester. It was noted, however, that students remembered little of group statements from the first semester. To encourage students to revise the knowledge gained in the first semester a small class test (Test 1 ) on group statements was introduced on the first day of classes of the second semester. Students had prior knowledge of this test and they were expected to prepare for the test during the recess.

\subsection{Modelling software}

To provide students with a more practical approach to group statements, spreadsheet software in the format of a consolidation model was made available to them after writing Test $l$ on the first day of the second semester. The purpose of the consolidation model is to enable students to apply their knowledge of group statements (specifically consolidations) and their IT skills in a practical scenario. The experience that students gained by completing the consolidation model was used to investigate whether the integration of IT skills with financial accounting had enhanced their learning experience of financial accounting, or not.

The consolidation model was prepared to test specifically whether students understand the underlying flow of information from the separate financial statements of group companies to the consolidated financial statements. This is done to emphasise the preparation of consolidated financial statements, since as mentioned before, this is the area of group statements that students tend to neglect. Therefore the financial statements of the parent and subsidiary company together with the consolidation journals (that include intergroup transactions) that are necessary to draft the consolidated financial statements were all provided to students.

Students were expected to complete a consolidation worksheet, which in essence required them to add the correct amounts from the group companies and the consolidation journals in order to calculate consolidated amounts for each line item present in the financial statements of the individual group companies. The consolidation worksheet is automatically linked to the group financial statements and thus provides immediate feedback to students as to the impact of their consolidation procedures (performed on the consolidation worksheet) on the group financial statements. The consolidation worksheet was automatically linked to the group financial statements, since Wynder (2004:233-234) found that receiving immediate feedback is essential to learning in general. To ensure that students do not perform their own calculations and enter these amounts into the consolidation worksheet, thus effectively by-passing the thought process of preparing consolidated financial statements, instructions given prohibits students to type in any amounts in the consolidation worksheet. Instead, students must use formulas to link the line items on the consolidation worksheet to the provided individual financial statements of the group companies and the consolidation journals. This forces students to perform the consolidation model without performing additional written calculations, which is a truer reflection of how things are done in practice and also ensures that students use IT skills to complete the consolidation model.

Students were given two weeks to complete the consolidation model. This time frame ensured that students submitted their work before the lectures on group statements commenced in the second semester. 


\subsection{Written assessments}

As mentioned in section 4.1, students were given Test 1 on group statements on the first day of the second semester. The purpose of the assessment was to test whether they knew the basic consolidation procedures and were able to draft consolidated financial statements. Therefore, the financial statements of the individual group companies and the consolidation journals were presented as information to the students. Students were required to use this information to calculate certain consolidated amounts that would form part of the consolidated financial statements. Test 1 was used to assess students' knowledge of group statements before they were exposed to the consolidation model. Test 1 was thus used as a control to see whether the completion of the consolidation model affected student performance.

After the completion of the consolidation model, the students were given substantially the same class test (Test 2) as Test 1 , as an unprepared class test. Superficial changes were made to the original test to ensure that students did not recognise it as being the same as Test 1 . Substantially the same test was used to ensure that Test 1 could act as a control for Test 2 . Any change in students' results from Test 1 to Test 2 was considered to be as a result of the completion of the consolidation model.

Between the two tests an unrelated topic was taught in class, thus ensuring that the only contact students had with group statements during this time was the completion of the consolidation model. Test 2 was given as an unprepared test to ensure that students did not study for the test. This was done to mitigate the risk that the results of the second test would be influenced by anything but the learning experience gained by completing the consolidation model. Since Test 1 and Test 2 was essentially the same, the solution to Test 1 was not available to the students. The solution to the consolidation model was not available to the students either before Test 2 was written. Once again, this approach was followed in an attempt to eliminate any other form of learning besides the learning from completing the consolidation model, which could affect the results of Test 2 .

Test 1 was written by 353 out of a possible 412 (86\%) registered students and 239 (58\%) wrote Test 2. To ensure that the average class mark of Test 1 was not affected by students who did not write Test 2, the results of students who did not write Test 2 were disregarded. This resulted in a sample of 239 students who had written both class tests. These results were summarised and compared against each other to see whether the completion of the consolidation model had an effect on the performance of students. The results of the two tests are discussed in section 5 .

\subsection{Questionnaire}

After students had completed the consolidation model and Test 2, a questionnaire was presented to them in their formal financial accounting class. The questionnaire included questions to assess the perceptions of students with regard to the benefits and disadvantages of completing the consolidation model. To ensure that the results of the two class tests did not affect the students' opinion of the consolidation model, no results were made available to students before the completion of the questionnaire. Students were asked to complete the questionnaire anonymously and to hand their completed questionnaire in at the end of class. Students' participation in the survey was voluntary.

From the total population of 412 students, 300 completed and usable questionnaires were obtained, resulting in a response rate of $73 \%$. Data from the questionnaires was manually 
imported into Microsoft Excel, where it was processed to draw conclusions. The answers to openended questions were analysed and summarised in like categories. The results of the questionnaire are discussed in section 5 .

\section{RESULTS}

To answer the first research question (namely whether the integration of IT skills with financial accounting has an effect on students' performance), the results from the written assessments as well as those from the questionnaire were used. This made it possible to draw conclusions on whether the completion of the consolidation model had an effect on students' performance on group statements as measured by using conventional assessment methods and by investigating students' perceptions of their performance (thus whether students felt that they understood group statements better after completing the consolidation model). The results of the written assessments are presented in section 5.1 and those of the questionnaire relating to the first research question are presented in section 5.2. The second research question (namely whether a more practical approach to a financial accounting topic have an effect on students' attitude towards the topic) was answered by investigating students' perceptions of their motivation towards group statements as obtained from questions asked to them in the questionnaire. The results of the questionnaire relating to the second research question are presented in section 5.3.

\subsection{Written assessments}

The average results of the two tests were compared to see whether there was a change in the performance of students when measured by using conventional assessment methods. The results are presented in TABLE 1 .

\section{TABLE 1: Results of written assessments}

\begin{tabular}{lc}
\hline & Percentage \\
\hline Average mark for test 1 & 57 \\
Average mark for test 2 & 73 \\
Average increase per student & 16 \\
Median increase & 17 \\
Maximum increase for individual student & 75 \\
\hline Maximum decrease for individual student & -42 \\
\hline Percentage of students showing an increase in results & 68 \\
\hline Percentage of students showing a decrease or no improvement in results & 32 \\
\hline
\end{tabular}

Source: Author's calculations

An average increase of $16 \%$ was noted from Test 1 to Test 2. After the completion of the consolidation model, $68 \%$ of students showed an increase in their results with only $32 \%$ showing a decrease, or no change in their results. It is thus clear that the results were not driven by a few students who showed a significant increase in their results, but that the majority of students showed an increase in their performance after the completion of the consolidation model. This 
suggests that the completion of the consolidation model did improve students' understanding of the topic and resulted in a measurable improvement in their performance.

\subsection{Students' perceived effect on their performance}

To investigate students' perceptions of whether the consolidation model had an effect on their performance, they were asked whether they felt that the completion of the consolidation model had improved their understanding of group statements. Students were required to use a five-point Likert scale varying from 'Definitely not' to 'Yes definitely'. The results are presented in TABLE 2.

TABLE 2: Perceived improvement in the comprehension of group statements

\begin{tabular}{lcc}
\hline & $\begin{array}{c}\text { Keyon Likert } \\
\text { scale }\end{array}$ & $\begin{array}{c}\text { Percentage of } \\
\text { total respondents }\end{array}$ \\
\hline Definitely not & 1 & 5 \\
No & 2 & 12 \\
Indifferent & 3 & 35 \\
Yes & 4 & 36 \\
Yes definitely & 5 & 13 \\
\hline
\end{tabular}

Source: Author's calculations

The mean value for the question was 3.4 with a standard deviation of 1.004 . The results indicate that most students perceived the consolidation model to have improved their understanding of the topic. This was interpreted as indicating that students felt that the completion of the consolidation model had improved their performance, since it could be expected that an improvement in understanding will lead to an improvement in performance.

Students were given the opportunity to list which aspects of the consolidation model they found to be of most value (an open-ended question). Of the 300 respondents 59 did not list anything. The results from the remaining 241 respondents that answered the question were summarised in similar categories which are presented in TABLE 3 . Respondents could list more than one aspect; therefore the total exceeds $100 \%$.

Of the respondents, $31 \%$ indicated that the improvement in their understanding of the relevant technical topic was the most valuable aspect of completing the consolidation model. It is noteworthy that this was an open-ended question and that students were not prompted or guided, but were allowed to give their own opinion. This further validates the finding that respondents felt their performance would improve after completing the consolidation model.

$21 \%$ of respondents listed the integration of their IT skills with financial accounting as a valuable aspect of completing the consolidation model. This illustrates that the integration of the pervasive skill (IT skills) with a technical subject such as financial accounting improved the learning experience of students which will be reflected in the performance of respondents. 
TABLE 3: Valuable aspects of consolidation model

\begin{tabular}{lc}
\hline & $\begin{array}{c}\text { Percentage of } \\
\text { respondents }\end{array}$ \\
\hline Improved understanding of the topic & 31 \\
Integration of IT skills with financial accounting & 21 \\
Revision & 17 \\
Practical application of theory & 7 \\
Immediate feedback & 5 \\
\hline Focus on preparation of financial statements and not on calculations & 5 \\
\hline Other & 24 \\
\hline
\end{tabular}

Source: Author's calculations

This also supports Boyce's (1999) and SAICA's (SAICA, 2010) claim that computer-assisted learning has the potential to increase educational outcomes significantly. The 'other' valuable aspects mentioned by $24 \%$ of respondents covered a wide range of categories, none of which represented more than $4 \%$ of respondents.

$93 \%$ of respondents also indicated that the consolidation model must also be presented to the next year's students and $66 \%$ of respondents indicated that they would also like to complete similar projects for other financial accounting topics. To determine whether there is a relation between students indicating that the consolidation model must be presented to the following year's students or that it must be completed for other topics as well and whether they felt that it improved their performance, ANOVA tests were performed. The results are presented in TABLE 4.

TABLE 4: Relation between the continuing integration of IT skills with financial accounting and students' performance

\begin{tabular}{lcccc}
\hline \multicolumn{3}{l}{ Students perceived effect on their performance as measured by Likert scale (refer to TABLE 2) } \\
\hline & $N$ & Mean & $\begin{array}{c}\text { Std. } \\
\text { deviation }\end{array}$ & $\begin{array}{c}p- \\
\text { value }\end{array}$ \\
$\begin{array}{l}\text { Students indicating the consolidation } \\
\text { model must be presented to next year's } \\
\text { students }\end{array}$ & 277 & 3.51 & 0.93 & $<.01$ \\
$\begin{array}{l}\text { Students indicating that the consolidation } \\
\text { model should not be presented to next } \\
\text { year's students }\end{array}$ & 19 & 2.05 & 1.03 & \\
$\begin{array}{l}\text { Students indicating further integration } \\
\text { with other topics should be done }\end{array}$ & 196 & 3.63 & 0.88 & $<.01$ \\
$\begin{array}{l}\text { Students indicating further integration } \\
\text { with other topics should not be done }\end{array}$ & 96 & 2.96 & 1.11 & \\
\hline
\end{tabular}

Source: Author's calculations 
The mean value for students indicating that the consolidation model be presented to the following year's students was 3.51 , which is significantly higher $(p$-value $=<.01)$ than the mean value for students indicating that they did not think the consolidation model should be presented to the following year's students. The mean value for students that indicated they would like similar projects (thus the integration of IT skills) for other financial accounting topics was 3.63 , which is also significantly $(p$-value $<.01)$ higher than the mean value for students that would prefer not to have similar projects for other topics. These results show that students who prefer that the consolidation model be presented to the next year's students and students who would like similar projects for other financial accounting topics, also felt that the completion of the consolidation model had improved their performance. This further supports the finding that students find the consolidation model to make a positive contribution to their learning experience of the related topic.

Students were also asked which aspects of the consolidation model they enjoyed. Once again an open-ended question was presented to respondents to give them the opportunity to give their own opinions without being guided. The results, which are presented in TABLE 5 , are very similar to those presented in TABLE 3. Of the total number of respondents 44 did not list anything; therefore they were excluded from the results shown in TABLE 5 . Since respondents were able to list more than one aspect, the total exceeds $100 \%$.

\section{TABLE 5: Enjoyable aspects of the consolidation model}

\begin{tabular}{lc}
\hline & $\begin{array}{c}\text { Percentage of total } \\
\text { respondents }\end{array}$ \\
\hline Integration of IT skills with financial accounting & 34 \\
Ease of using the consolidation model & 15 \\
Immediate feedback & 13 \\
Improved understanding & 10 \\
Time saving & 9 \\
Other & 19 \\
\hline
\end{tabular}

Source: Author's calculations

The most enjoyable aspect as listed by the respondents was the integration of their IT skills with financial accounting (34\%). This corresponds with the finding as reported in TABLE 3 and further validates the finding that the integration of the pervasive skill, IT skills, enhances the learning experience of financial accounting students. Some $10 \%$ of the respondents also listed an improvement in their understanding of the relevant topic to be an enjoyable aspect of the consolidation model. This once again corresponds with the results reported in TABLE 3 and further supports the finding that the completion of the consolidation model improved the students' performance.

It is interesting to note that $13 \%$ and $5 \%$ (refer to TABLE 3) listed 'Immediate feedback' as an enjoyable and valuable aspect of the consolidation model respectively. This corresponds with Wynder's (2004:233-234) finding that receiving immediate feedback is essential to learning in general. 
A further interesting finding is that $9 \%$ of respondents who indicated that they do not prefer the consolidation model to be presented in an electronic format, stated as reason for their preference that the electronic format does not assist them with preparation for examinations. These answers were derived from an open-ended question. This finding supports the critique by Botha (2001:50) that passive teaching methods combined with traditional assessment methods lead to students focussing on passing examinations rather than understanding and applying the theoretical concepts. Overall, the evidence suggested that respondents found the consolidation model to be a valuable learning tool and that it enhanced their understanding of the related topic which could lead to an improvement in their performance.

\subsection{Effect on students' attitude toward the related topic}

Respondents felt more motivated to study group statements after the completion of the consolidation model (indicated by $62 \%$ of respondents). Furthermore, $72 \%$ of respondents also indicated that they felt more motivated to complete the project since it was in electronic format rather than in paper format. This provides evidence that a more practical approach to a technical financial accounting topic (including doing projects for the topic) motivates students to study the topic and to understand it rather than merely to memorise its principles.

Students were also asked whether they preferred to complete projects that are in an electronic format rather than in a written format, and $78 \%$ of respondents indicated that they preferred the project to be in an electronic format. Of the $78 \%$ of respondents that indicated that they preferred an electronic project, $26 \%$ indicated (by answering an open-ended question) that the motivation for their choice was the practical experience gained by completing the project electronically. This also corresponds with practical experience gained being one of the aspects that the respondents found to be of most value in completing the consolidation model. This result supports the suggestion made by Marriott (2004:59) and SAICA (SAICA 2010: 8) that the integration of IT skills and accounting education should help students to better apply technical knowledge. Overall, the results suggest that the consolidation model improved respondents' interest in and attitude towards group statements.

\section{CONCLUSION}

This study investigated whether the pervasive skill, IT skills, can successfully be integrated with the technical core subject financial accounting in such a way that the technical knowledge of the student is enhanced as a result of the integration. Students were required to complete a consolidation model that integrated IT skills and group statements (a topic of financial accounting). Two formal assessments (one acting as a control) were used to determine whether the completion of the consolidation model affected students' performance in group statements. A questionnaire was also used to investigate whether students felt that the consolidation model affected their performance and whether it had an effect on their attitude towards group statements and financial accounting.

The results showed an increase in students' results (as measured by the formal assessments) after the completion of the consolidation model. Responses from the questionnaire also suggested that students felt that the consolidation model had improved their understanding of group statements and thus could have a positive effect on their performance; and that the completion of the 
consolidation model improved students' attitude toward group statements, thus resulting in a more positive learning experience.

The results further support Boyce's view (1999:195) that the integration of IT skills with a core subject is of value to students when it is used to teach technical and practical knowledge. Overall, the results suggest that the pervasive skill, IT skills, can be successfully integrated with the technical core subject, financial accounting. The integration results in a more practical approach to group statements and can thus successfully be used by educators to reduce the gap between accounting education and the expectations of the accounting profession.

As with similar studies a limitation of this study is that students have different learning styles (Marriott, 2002), which could affect the results (this aspect does not fall within the scope of this article). A further limitation is that students could have studied material other than the consolidation model, which could have an impact on the results.

Further studies could investigate the effect of integrating other pervasive skills with core subjects on student performance. It would also be of interest to investigate whether IT skills can be successfully used to integrate two or more core subjects with each other. This will further expose students to a more practical experience and will give them a view of how the combination of core subjects' technical knowledge is applied in the business world, which would further reduce the existing gap between accounting education and the expectations of the accounting profession.

\section{LIST OF REFERENCES}

Ballantine, J. \& McCourt Larres, P. (2009). Accounting undergraduates' perceptions of cooperative learning as a model for enhancing their interpersonal and communication skills to interface successfully with professional accountancy education and training, Accounting Education: an international journal, 18(4-5), pp. 387-402.

Barac, K. (2009). South African training officers' perceptions of the knowledge and skills requirements of entry-level trainee accountants, Meditari Accountancy Research, 17(2), pp. 19-46.

Barac, K. \& Du Plessis, L. (2014). Teaching pervasive skills to South African accounting students, Southern African Business Review, 18(1), pp. 53-79.

Barnett, R. (2009). Knowing and becoming in the higher education curriculum, Studies in Higher Education, 34(4), pp. 429-440.

Benke Jr, R.L. \& Hermanson, R.H. (1991). Teaching and learning with microcomputers, Strategic Finance, 73(3), pp. 60.

Borthick, A.F. \& Curtis, M.B. (2008). Due diligence on fast-fashion inventory through data querying, Journal of Information Systems, 22(1), pp. 77-93.

Botha, W.J.J. (2001). Pre-qualification education of registered accountants and auditors in South Africa: Perspectives on whether the education process is normatively justifiable, Meditari Accountancy Research, 9(1), pp. 33-59.

Boyce, G. (1999). Computer-assisted teaching and learning in accounting: pedagogy or product?, Journal of Accounting Education, 17(2), pp. 191-220. 
Boyce, G., Williams, S., Kelly, A. \& Yee, H. (2001). Fostering deep and elaborative learning and generic (soft) skill development: the strategic use of case studies in accounting education, Accounting education, $10(1)$, pp. 37-60.

Bui, B. \& Porter, B. (2010). The expectation-performance gap in accounting education: an exploratory study, Accounting Education: an international journal, 19(1-2), pp. 23-50.

De Lange, R., Marx, B. \& Van der Watt, A. (2013). Sustainability in education: an evaluation of a new teaching and learning strategy in chartered accountancy studies - a student perspective, Journal of Economic and Financial Sciences, 6(2), pp. 285-308.

De Villiers, R. (2010). The incorporation of soft skills into accounting curricula: preparing accounting graduates for their unpredictable futures, Meditari Accountancy Research, 18(2), pp. 1-22.

Fortin, A. \& Legault, M. (2010). Development of generic competencies: Impact of a mixed teaching approach on students' perceptions, Accounting Education: an international journal, 19(1-2), pp. 93122.

Gammie, B., Gammie, E. \& Cargill, ع. (2002). Personal skills development in the accounting curriculum, Accounting Education, 11(1), pp. 63-78.

Helmi, M.A. (1986). Integrating the microcomputer into accounting education-approaches and pitfalls, Issues in Accounting Education, 1(1), pp. 102-111.

Hesketh, J. (2011). Accounting academics' multiple challenges: Issues-driven learning offers a way forward, South African Journal of Accounting Research, 25(1), pp. 1-34.

Horsfield, L. (1995). Factors to consider when choosing a computerized case study for an undergraduate auditing course, Accounting Education, 4(4), pp. 297-318.

Izard, C.D. \& Reeve, J.M. (1986). Electronic spreadsheet technology in the teaching of accounting and taxation - uses, limitations, and examples, Journal of Accounting Education, 4(1), pp. 161-175.

Leidner, D.E. \& Jarvepaa, S.L. (1995). The use of information technology to enhance management school education: A theoretical view, MIS quarterly, pp. $265-291$.

Marriott, N. (2004). Using computerized business simulations and spreadsheet models in accounting education: a case study, Accounting Education, 13(1), pp. 55-70.

Marriott, P. (2002). A longitudinal study of undergraduate accounting students' learning style preferences at two UK universities, Accounting Education, 11(1), pp. 43-62.

Montaño, J.L.A., Cardoso, S.M.J. \& Joyce, J. (2004). Skills development, motivation and learning in financial statement analysis: an evaluation of alternative types of case studies, Accounting Education, 13(2), pp. 191-212.

Müller, દ. (2011). Why CAs are good for SA. Available: http://www.moneyweb.co.za/archive/why-casare-good-for-sa/. (Accessed 7 April 2015).

Noor Azizi, I. (2009). Accounting information system: Education and research agenda, Malaysian Accounting Review, 8(1), pp. 63-80.

SAICA (South African Institute of Chartered Accountants). (2010). Competency Framework: Detailed Guidance for Academic Programmes - Competencies of a Chartered Accountant (SA) at the Point of Part 1 Examination (Assessment of Core Technical Knowledge). Johannesburg: SAICA.

Siegel, P.H., Omer, K. \& Agrawal, S.P. (1997). Video simulation of an audit: an experiment in experiential learning theory, Accounting Education, 6(3), pp. 217-230. 
Springer, C.W. \& Borthick, A.F. (2004). Business simulation to stage critical thinking in introductory accounting: Rationale, design, and implementation, Issues in Accounting Education, 19(3), pp. 277303.

Togo, D.F. \& McNamee, A.H. (1995). Computer integration into the accounting curriculum: Learning benefits, problems, and guidelines, Journal of Accounting Education, 13(2), pp. 149-158.

Wessels, P. (2005). Critical information and communication technology (ICT) skills for professional accountants, Meditari accountancy research, 13(1), pp. 87-103.

Wessels, P. (2008). The identification and discussion of strategies for implementing an IT skills framework in the education of professional accountants, South African Journal of Accounting Research, 22(1), pp. 147-181.

$\mathrm{Wu}$, F.H. (1984). Teaching managerial (cost) accounting with electronic spreadsheet software, Issues in Accounting Education, 1(1), pp. 81-97.

Wynder, M. (2004). Facilitating creativity in management accounting: a computerized business simulation, Accounting Education, 13(2), pp. 231-250. 